Orissa Journal of Commerce

Vol. 42, Issue 2, April-June 2021

ISSN: 0974-8482

(C) OJC India. All Right Reserved

URL: www.ojcoca.org

DOI: https://doi.org/10.54063/ojc.2021.v42i02.04

\title{
Developing and Validating Financial Inclusion Measuring Scale for Rural Inhabitants in Tamil Nadu
}

\author{
Prabaharan Natarajan ${ }^{1}$ and Sheik Abdullah Sulaiman ${ }^{2}$ \\ ${ }^{1}$ Research Scholar, PG \& Research Department of Commerce, Pasumpon Muthuramalinga Thevar College, Tamil Nadu. \\ E-mail: prabakuvalai@gmail.com \\ ${ }^{2}$ Assistant Professor, PG \& Research Department of Commerce, Pasumpon Muthuramalinga Thevar College, Tamil Nadu. \\ E-mail: professorsheikabdullah@gmail.com
}

To cite this paper

Natarajan, P., \& Sulaiman, S.A. (2021). Developing and Validating Financial Inclusion Measuring Scale for Rural Inhabitants in

Tamil Nadu. Orissa Journal of

Commerce. 42(2), 41-52

Keywords

Financial empowerment, Financial inclusion, Rural inhabitants, Generalization of scale, Principal component analysis.

JEL Classification

R11, G10, G21, C18

\begin{abstract}
The rural penetration of banking products is very low in India. The inclusion of financial resources aids the availability of financial services with ease, maximizes business opportunities, and outsources financially literate people among the rural inhabitants. The key focus of this research study is to develop and validate the scale for measuring financial inclusion. The psychometric scale development for financial inclusion is developed through three distinguished ways viz: inductive, deductive, and combination of both. The present study adopted the inductive method to validate the scale because of its feasibility and wide usage. The validated scale determines financial inclusion and its initiation taken by banks towards rural inhabitants in the state of Tamil Nadu. The probability sampling technique is employed to identify the sample of respondents. Factor Analysis is run to find the pattern relations. The Exploratory Factor Analysis result reveals that the study has developed scales that are loaded in four distinguished dimensions namely usage of financial service, financial access, service quality, and financial welfare.
\end{abstract}

\section{Introduction}

Financial empowerment of rural and urban inhabitants is accelerated through strong financial inclusion initiatives. The timely delivery of quality financial service assessed by citizens will enable more empowerment, be it social, economic, and political. One of the ways to control poverty through inclusive development is specifically designed for rural inhabitants. The computational statistics studied in the year 2011 in India, found 55 percent of the rural households being financially excluded in Tamil Nadu alone. On the other hand, the urban inhabitants' participation and access to financial services accounted for 60.37 percent. Under the economy of developed countries, there is substantial progress backed up by effective financial systems. Financial inclusion initiatives are also being developed to aid the developed economy. It helps the inhabitants utilize these financial services efficiently and promote the country's economy. Many countries which have already been listed in the developed and the 
underdeveloped have a different regulatory framework to concentrate more on delivering effective financial inclusion initiatives. The major trouble in enhancing effective inclusion is its implementation. In this connection, the present study is conducted by the researcher to develop and to a systematic measurement scale for financial inclusion from the perspective of rural inhabitants in Tamil Nadu.

\section{Review of Literature}

There are few studies conducted with the perception of rural inhabitants towards financial inclusion at the national and international level along with a new scale development and validation. The present study aims to collect the comprehensively related literature in financial inclusion and another measurement of scale. This would help to form the hypothetical measurement model for financial inclusion in different constituent factors in a pre-run pilot study. After validation, the study aims to conduct the same in a more comprehensive manner across India. The researcher has taken many insights from renowned theorists like Smith.A, Yunus, and others to validate the base of financial inclusion.

The economist Smith (2002) stated "No society can surely be flourishing happy without the greater part of the poor and miserable" and also supported by Noble Laureate Yunus in his key-note address on receiving Nobel Prize said, "Poverty is not created by poor people; it is an outcome of the failure of the framework and policies". The primary key of all the developing and the developed economy is to eradicate poverty through financial inclusion. Josiah and Elizabeth (2012) state that financial inclusion and its initiatives are very crucial factors for economic development. It is strongly believed by both high-income as well as low-income countries. Many Researchers and Government bodies believed the same. The financial sector's progress is considered a prerequisite for an economic hike and eradicates poverty (Chibba, 2009).

The financial inclusion policy enables people to use banking products and services in unbanked areas. Banking systems play a pivotal role in developing the financial system. Kochaar (2009) that system offer financial services are available to every individual to do banking transactions. Apart from that rural inhabitants are facing many constraints when they access banking products (Basu et al., 2005). 'Accessibility' to financial resources is found as the key parameter of Rural and Urban households. More technological and human approaches are essential for strengthening the enabling and evaluation of financial inclusion (Serrao et al., 2012). Also, systematically disadvantaged groups always exclude themselves from inclusive development, especially rural inhabitants. This is a very critical context to examine the protocol of rural habitant's wealth impacted through financial inclusion initiated by banks in India.

Scale development is very important in the stream of social sciences and humanities. Moreover, it is also a very common and habitual procedure. This has a set of complicated rules and techniques for feasible scale development. Many researchers have articulated many ideas for many years to generate measurement scales. The most accepted scales include the generalised scale for financial inclusion which is developed by Sarma and Pais (2011). In the present study, the researcher has endeavoured to blend the past as well as the present financial inclusion scales to arrive at more accurate and feasible findings. The researcher's articulated scales thus developed have many similarities with the one framed 
by the RBI. The only difference between the scale developed by the researchers and National Strategy for Financial Inclusion 2019-2024 is that the former relates with primary data while the latter deals with secondary data.

The present study is undertaken to analyze the views of rural inhabitants towards financial inclusion initiatives by the banks. Before executing the study, the researcher has generalized the scale for measuring financial inclusion. After successful validation, the research will be carried out. In this regard, the paper attempts to validate and generalize 20 -item scale for measuring financial inclusions.

\section{Background}

The other way to define financial inclusion is that it ensures each household to have access to financial products \& services. For offering a sustainable economy and social development, the particular country should have strong financial inclusion practices. The robust financial inclusion initiative enables the empowerment of the socially excluded, the poor and women, to make them equipped to make the right financial decisions on their own. The inclusion of weaker sections in the society and imparting of the financially oriented access is universally called "Financial Inclusion". These initiatives insist the excluded society access more financial services like handling bank accounts, utilizing financial products for various reasons such as credit insurance, accessing the subsidy from the government, and so on. The problem with the dimension of demand is when it gets recovered the Indian economy eradicates the low-income groups, the ones with the lack of financial literacy and have more than one bank account in a family. The other problematic side is that financial inclusion has issues with supply, which are positively associated with bank penetration. Poor banking penetrations are the least in number with bank branches, failing to offer suitable banking products to the poor income groups, problems in execution, and barriers in communication. All these factors affect financial inclusion in the form of the supply-side by the financial institution.

During the last decade, timely policy decisions and huge investments have been availed by national and state levels in India. Many different measures and initiations have been taken by the union government and state body in respect to financial institutions. In addition, a huge interest is required for policy decisions and effective administration informing and delivering new initiations in financial services. The banking institution in India plays a very important role in enhancing the efficient financial inclusion of products and services. The initiations not only end itself with public sectors, but also private sectors who offer these services to compete with the public banks and offer services to the financially excluded society in general. Moreover, the banking sector has adopted a world-class proven initiation framework to serve society and impart them into financial inclusion.

The concept of financial inclusion has two distinguished elements that are good decision making on investment and also access the products and services in financial sectors. Access to financial services promotes self-confidence and empowerment among the users. The central governing institution RBI and the Indian government have taken much more continuous efforts to offer and increase effective financial inclusion practices and measures. Generally, accessing financial sources is available in the form of reports of the particular institution. The reports aid in assessing banking penetrations. But it is not the only factor to decide financial inclusion. The other factors include customers' perspective in 
research, mapping of the best models from universal players, and empirical model validations that do not form a part of the report.

\section{Objectives of the Study}

The main objectives of the study are:

- To generalize and validate the scale for measuring financial inclusion.

- To determines the financial inclusion and its initiation taken by banks towards rural inhabitants in Tamil Nadu.

\section{Methodology}

\subsection{Data Sources and Samples Size}

This study is not only descriptive but also empirical in nature and approach. It analyses the views of rural customers towards financial inclusion initiatives taken by banks in Tamil Nadu. The data are collected through a structured interview schedule. Many versions of the scale are available to measure financial literacy in different dimensions (Chen and Volpe, 1998; Mandell, 2008; Klapper et al., 2015). These scales are only addressed to measure financial literacy. For analysis, the scale items are recoded as identifiable code such as (FI 1 to FI 20).

The scale is measured through the Likert five-point scaling technique ranging from Strongly Agree to Strongly Disagree. For high content and face validity, the schedule is administrated based on recommendations given by academicians and experts in the banking sector. The data collected are from the rural people of Tirunelveli district in Tamil Nadu's province. The rural mapping of collected samples is identified through records availed in the administrative office of the particular district. Going by the derivations of the Cochran sample size formula, the total population of the area taken for the study is 15,57,004 (uidai.govin). As per the data provided by the District Collector office, there are 13 rural blocks in the district. According to the above formula, 5 percent confidence and 5 percent interval level the selected sample size is 193. Computing the data, the researcher could find that 193 samples are distributed equally to 13 blocks. Since the block sample size was unequal $(193 / 13=14.84 \%)$. 15 samples selected through probability sampling are equally distributed among the 13 blocks. Finally, 177 sampled respondents are fit for data analysis. The sample response rate is 91.70 percent, which is more admissible for analysis in behavioural research.

\subsection{Approach of Scale Development}

Measurement scales are a very essential tool, it enables the researcher to discover a new theory and fill the research gap which is to be filled. Scale development study is a scientific approach for seeking solutions to problems. But it is not an easy task, more complex procedures have to be followed until a systematic validation is reached; (Clark and Watson, 1995; Morgado et al. 2017).

The first step of scale development begins with generating the scale items, which is derived by the researcher through a strong theory. There are many methods to generate the scale and the widely accepted methods are inductive, deductive and the rest is a combination of both. Each method has its 
pros and cons adopted based on the researcher's interest, as much as the availability of theories, objectives of the research, and feasibility. The deductive method of scale generation may be applied by the researcher when the scale is derived from the existing comprehensive literature and the scale formerly utilized by someone (Hinkin, 1995). In the inductive method, the base of scale item is developed through the opinions gathered from the subject experts in respect to qualitative information (Kapuscinski and Masters, 2010). Thus, the method may help the researchers to develop the measurement scale from the strategy which is under study. Like the way, the present study has been executed by the researcher through RBI-National Strategy for Financial Inclusion (2019-2024) by the opinions derived from the panel of experts. After their opinions, the researcher has developed the scale as 20 items to measure financial inclusion from the perspective of rural inhabitants. The face and content validities are also evaluated by the panel of experts and potential users. Their recommendations are invited by the researcher and redefined and reframed accordingly.

The last stage of the scale development process is checking the construct validity and reliability of the measurement items. In the present study, the construct validity is evaluated through Exploratory Factor Analysis (EFA) and the scale item reliability is tested through many ways such as internal reliability using Cronbach test, test re-rest, and split-half method. Many researchers have argued that the combination of both Exploratory Factor Analysis (EFA) and Confirmatory Factor Analysis (CFA) is an efficient way to evaluate the measurement scale or theory. In most of the studies in scale development, the majority of the researchers have chosen EFA as the best way to check the construct validity rather than CFA (Bakar and Mustaffa, 2013). The data analysis has been carried through the application of the IBM-SPSS 21 version.

\section{Results and Discussion}

\subsection{Exploratory Factor Analysis}

The sampled respondent of this study area belongs to different rural regions of the state province, the demographic classification of collected respondents out of 177, 64.97 percent male respondents, 45.23 percent of them completed higher schooling, 39.73 percent have monthly income of below Rs.15,000 and 48.95 percent of the respondents use electronic banking instead of directly visiting the bank nearer to their residence. Many demographic variables are taken for analysis during that time countable outliers fought by the researcher and its holdout by the researcher for further analysis.

To run the Exploratory Factor Analysis (EFA) the multivariate analysis assumptions are carefully considered for obtaining effective results for empirical evidence. The major prerequisite criteria for applying EFA is viz. the data should be normally distributed and free from multicollinearity, adequacy of data and the correlation matrix should be an identity matrix.

The sampling adequacy and matrix determinant are evaluated by KMO and Bartlett's test. If the value of $\mathrm{KMO}$ is less than 0.50 it should not be adequate to apply the factor analysis for collected data (Hair et al. 2009) and Bartlett's test for Sphericity is statistically significant $(\mathrm{P}<0.05)$. After fulfilling these criteria, the researcher has analyzed the percentage of explained variance by each dimension and the rotated factor matrix table was examined for efficient structure detection by the researcher proposed 
Prababaran Natarajan and Sheik. Abdullab Sulaiman

conceptual scale for measuring the financial inclusion initiatives. Further Cronbach alpha test was applied by the researcher to assess the scale developed for the study to check the reliability of each dimension.

Table 1: Mean and Standard Deviation Values of the Financial Inclusion Scale

\begin{tabular}{|c|c|c|c|}
\hline Recode & Statements & Mean & Std. Deviation \\
\hline FI1 & I regularly access the financial institutions, whenever a financial need arises & 3.7627 & .91090 \\
\hline FI2 & $\begin{array}{l}\text { The bank continuously intimates me up-to-date information about new } \\
\text { products and services }\end{array}$ & 3.7175 & .97081 \\
\hline FI3 & I am okay with utilizing E-services provided by banks & 3.9718 & .90723 \\
\hline FI4 & $\begin{array}{l}\text { Accessing the banking personnel is very comfortable when I encounter } \\
\text { problems }\end{array}$ & 3.0960 & 1.06432 \\
\hline FI5 & I never think my bank is far away from me during a financial crisis & 3.7232 & .96952 \\
\hline FI6 & $\begin{array}{l}\text { Banks offer quality products and services, which satisfy my financial } \\
\text { expectations }\end{array}$ & 3.6102 & .87938 \\
\hline FI7 & $\begin{array}{l}\text { My bank representative clearly explains the terms and conditions of } \\
\text { products and services }\end{array}$ & 3.4576 & .91680 \\
\hline FI8 & $\begin{array}{l}\text { My bank maintains better relationship marketing practices to approach } \\
\text { the customers }\end{array}$ & 3.6497 & .94833 \\
\hline FI9 & The navigation of online banking is easy to proceed with the transactions & 3.4802 & 1.01741 \\
\hline FI10 & My bank is technically strong and it is not difficult to make transactions & 3.3220 & 1.03530 \\
\hline FI11 & I always utilize the services offered by banks to a larger extent & 3.5311 & .88574 \\
\hline FI12 & My bank offers a wide range of value-added services & 3.7345 & .97852 \\
\hline FI13 & $\begin{array}{l}\text { I mostly prefer automated kiosks for depositing the fund and other } \\
\text { banking transactions }\end{array}$ & 3.6102 & .89855 \\
\hline FI14 & I am very much interested to pay my bills through online/mobile banking & 3.6271 & .92131 \\
\hline FI15 & $\begin{array}{l}\text { I strongly believe the bank products and services are mostly utilized } \\
\text { by rural inhabitants }\end{array}$ & 3.6102 & 1.01159 \\
\hline FI16 & I enjoy productive assets gain through financial inclusion & 3.6836 & .84033 \\
\hline FI17 & I strongly feel my living standard is very good & 3.7571 & .73296 \\
\hline FI18 & $\begin{array}{l}\text { Through financial investment, I can access and maintain standard } \\
\text { education, health \&hygiene }\end{array}$ & 3.7571 & .84124 \\
\hline FI19 & $\begin{array}{l}\text { I have sufficient awareness and knowledge about our country's } \\
\text { economic conditions }\end{array}$ & 3.6045 & .85386 \\
\hline FI20 & $\begin{array}{l}\text { I am willing to take risks to gain high returns from financial products } \\
\text { offered by banks }\end{array}$ & 3.7797 & .83396 \\
\hline
\end{tabular}

The descriptive statistics presented by mean and standard deviation. The highest value obtained is 3.9718 and the least value is also found as 3.090. The highest standard deviation arrived more than

46

Orissa Journal of Commerce, 42(2) (C) 2021 
once in three of four dimensions. Before considering the reliability issues in scale generalization, the researcher determines if the analytical data set is reliable to conduct factor analysis for the collected data. Before applying factor analysis for structure detection, the researcher should fulfil the statistical criteria for executing the factor analysis model. Before the factor analysis model, the two initial criteria were analyzed by the researcher such as KMO \& Bartlett's test. The KMO test predicts the sampling adequacy. This test compares both the correlation and partial correlation in the analysis. The KMO test value should be more than or equal to 0.5 is more reliable. Kaiser (1974) has recommended many comparable values for the test of KMO. By following his barometers, the computed test value in the present analysis comes out to 0.899 , which is an acceptable value according to him. The other criteria of factor analysis are that the correlation matrix should be identical, which is proved in the present study. Bartlett's Test of Sphericity test value is 1.569 at $\mathrm{df} 190$ and the pvalue is less than a threshold value of 0.05 . It infers that the correlation matrix is significant for an identical matrix.

Table 2: Test of Sampling Adequacy and Checking of Identical Matrix

\begin{tabular}{llc}
\hline \multicolumn{2}{c}{ The measurements of Kaiser-Meyer-Olkin-Sampling Adequacy. } & \multicolumn{1}{c}{.899} \\
\hline Sphericity test is given by Bartlett & Chi-Square testing & 1569.736 \\
\cline { 2 - 3 } & degrees of freedom & 190 \\
\cline { 2 - 3 } & Significance & .000 \\
\hline
\end{tabular}

In general, EFA is widely used multivariate statistical analysis; it groups the large set of statements into a smaller set of components based on a correlations matrix. Many methods are used by the researcher universally but Principal Component Analysis (PCA) is the best method for empirical work i.e. theory-building piece of work strongly recommended by Costello and Osborne (2005) and another criterion for factor analysis is factor loading if the factor loading of particular statement is more than 0.6 is considered very effective. While at the same time, the factor loading of more than $0.5 \pm 0.03$ is more reliable (Klien, 2005). There is no hard and fast rule to decide the cut-off point, but generally, it is taken above 0.5 . If the extracted factor loading is less than 0.5 or the extracted factor cross-loaded with others is eliminated by the researcher. Through EFA, 20 statements were extracted as four components exposed from rotated components matrix output.

As shown in the above table the rotated sum of squared loading for the first dimension is 22.380 , that dimension Average variance extracted value is .489 and out of 177 sampled respondents, 44 respondents are given priority to the first dimension of financial initiatives taken by the banks. Under this dimension of financial inclusion, the factor 'My bank offers a wide range of value-added services' loading is .805 which is high among the other variables in the latent dimension. In respect to the second dimension accounted for 17.598 variances extracted by the factors while loading, no factors in extracted dimension factor loading is less than 0.5 so all the factors are retained by the researcher to generalize scale for financial inclusion. 
Prababaran Natarajan and Sheik. Abdullah Sulaiman

Table 3: Component Matrix after Rotation

\begin{tabular}{|c|c|c|c|c|}
\hline \multirow[t]{2}{*}{ Statements } & \multicolumn{4}{|c|}{ Component } \\
\hline & 1 & 2 & 3 & 4 \\
\hline FI12 & .805 & & & \\
\hline FI14 & .705 & & & \\
\hline FI15 & .682 & & & \\
\hline FI11 & .675 & & & \\
\hline FI13 & .614 & & & \\
\hline FI10 & & .765 & & \\
\hline FI8 & & .728 & & \\
\hline FI9 & & .715 & & \\
\hline FI7 & & .647 & & \\
\hline FI6 & & .521 & & \\
\hline FI3 & & & .582 & \\
\hline FI2 & & & .564 & \\
\hline FI4 & & & .530 & \\
\hline FI1 & & & .514 & \\
\hline FI5 & & & .511 & \\
\hline FI16 & & & & .796 \\
\hline FI17 & & & & .741 \\
\hline FI19 & & & & .552 \\
\hline FI20 & & & & .545 \\
\hline FI18 & & & & .532 \\
\hline Squared loadings & 22.380 & 17.598 & 9.187 & 9.007 \\
\hline Average Variance extracted & .489 & .511 & .292 & .446 \\
\hline *Cluster Membership & 44 & 45 & 51 & 37 \\
\hline
\end{tabular}

Note: Principal Component Analysis: (PCA) with varimax rotation

*Where K-means cluster test using factor scores

\subsection{Reliability and Validity of Financial Inclusion Scale}

After carrying out the factor analysis of the 20 -item scale which was measuring the financial inclusion perspectives among rural inhabitants under four-dimension, Cronbach's alpha test is found .767,. 799,. 766 , and .772 respectively. If the alpha value is more than 0.7 is considered more reliable (Straub et al,. 2004). In the present case, the results of Cronbach's alpha test reveal that the researcher has created scale items that are found more reliable and fulfil the reliability criteria. 
Developing and Validating Financial Inclusion Measuring Scale for Rural Inhabitants in Tamil Nadu

Table 4: Inter-Item Correlation Matrix among Four Dimensions of Financial Inclusion

\begin{tabular}{lcccc}
\hline Dimension(s) & $\begin{array}{c}\text { Usage of } \\
\text { Financial service }\end{array}$ & $\begin{array}{c}\text { Financial } \\
\text { Access }\end{array}$ & $\begin{array}{c}\text { Service } \\
\text { Quality }\end{array}$ & $\begin{array}{c}\text { Financial } \\
\text { Welfare }\end{array}$ \\
\hline Usage of Financial service & 1 & & & \\
Financial Access & .576 & 1 & & \\
Service Quality & .514 & .534 & 1 & \\
Financial Welfare & .579 & .600 & .676 & 1 \\
\hline
\end{tabular}

Significant $\mathrm{p}<0.01$ percent level

The convergent validity of four distinguished dimensions assessed by correlation matrix, the service quality dimension, and the financial welfare dimension correlation coefficient is .676 which is high than the correlation followed by service usage and financial welfare (.579), Service usage and financial access correlation coefficient is (.576). The lowest correlation coefficient was found between service usage and service quality dimension (.514). The results of the inter-item correlation matrix among four dimensions confirm the convergent validity of the Financial Inclusion measurement scale for the Indian context.

\section{Theoretical Dimension of Measuring Financial Inclusion}

Financial inclusion is a multi-phase concept with many components; it may not be relevant from one country to the other country. The following four dimensions are extracted by EFA, the scale developed by the researcher itself. The dimensions of financial inclusion can be defined, in order of context.

\subsection{Usage of Financial Service}

The main success factor for financial inclusive development ultimately begins with creating awareness. It is essential for success in financial inclusion (Rather and Lone, 2012). To improve the usage of banking products and services the bank should take necessary awareness programs to enhance the continuous usage of banking products. The usage dimension of financial inclusion concerned the usage of financial products is more than the basic adoption and usage. Moreover, it measures the perception and In-depth level of usage of financial products. To evaluate the usage, what kind of financial products are used by individuals and household utilized according to their preference.

\subsection{Service Quality}

The second dimension in measuring financial inclusion is quality. Quality service is one of the deciding factors of financial inclusion. The quality of products and services are fulfilling the needs of the customers. The perceived quality encompasses the experience, attitude, and opinion about the financial products and services available to the customer. The quality measure makes together a relationship between the financial institution and its users. The relationship impacted with understanding levels and choice of implication by the consumer.

Orissa Journal of Commerce, 42(2) (C) 2021 


\subsection{Financial Access}

The third component of financial inclusion measurement is named 'financial access'; it is concerned with the ability and uses of availability of service and products by the financial institution. To evaluate the access dimension, it should analyse the barriers which are accountable in opening and maintaining the bank accounts. A better understanding of the access dimension is evaluated through the gap proportion between several bank accounts and the population. The access data obtained easily because it is a source of information provided by the financial institution. But in the primary source of measuring this dimension is gathered in what extent the customers utilize the service to achieve their expectations.

\subsection{Financial Welfare}

The fourth dimension of measuring financial inclusion is, how well the effective inclusion policies will improve the wealth of consumers. Many theoretical models replicate that financial inclusion reduces wealth inequality (Dieter and Anna, 2020). A higher financial inclusion index is improving economic growth and reduces the poverty (Park and Mercado, 2018). It is very difficult to measure the outcome of welfare through financial products and services. By enhancing and improving bank business, the progress is tuned to improvising the customer base which will increase the welfare of the customer. The customer's financial welfare will result in effective financial decision-making in a dynamic environment.

\section{Conclusion}

The primary purpose of the present study is to evaluate the validity of the researcher's proposed psychometric scale for measuring financial inclusion. An independent financial inclusion 20 items scale is developed by the researcher. The structure detection proves that scales are loaded in the respective dimension. The structure detection is carried out with the support and assistance of Exploratory Factor Analysis (EFA), the result of factor analysis replicates that four dimensions are extracted, which all accounted to financial inclusion from the perspective of rural inhabitants in Tamil Nadu. It is very much possible to measure financial inclusion through this scale. To sum up, the development of the financial inclusion scale has provided an important contribution to the financial institution particularly for measuring the same. It is advisable that the user adopts extracted scale from this study, and validates the dimension with a large sample size by using various factor analyses to find construct validity. Furthermore, the present study is carried out with negligible limitations. The selected samples are considered as a pilot study for major research in the future. The researchers strongly recommend using the financial inclusion scale to validate any further research undertaken by other researchers and other academia.

The purpose of this research is to bridge the gap between income inequality and poverty. The financial inclusion will also help in removing the negative impacts of poverty. Through this study, the four variants in financial inclusion will pave way for scientific study. The customer perceptions can also be measured through the financial inclusion scale developed by the researcher. In the long run, the rural customer needs and wants on financial inclusion will be increased and improved in a better way. The most advantageous part of adopting financial inclusion to rural inhabitants will make their life 
more luminous. The study focuses on incorporating the aforesaid implications and helps to fill the research gap by developing a novel financial inclusion scale.

\section{References}

Bakar, H. A., \& Mustaffa, C. S. (2013). Organizational communication in Malaysian organizations. Corporate Communications: An International Journal, 18(1), 87-109.

Chen, H. \& Volpe, R.P, (1998). An Analysis of Personal Financial Literacy among College Students, Financial Services Review, 7(2), 107-128.

Chibba, M. (2009). Financial Inclusion, Poverty Reduction and the Millennium Development Goals. The European Journal of Development Research. 21, 213-230.

Clark, L. A., \& Watson, D. (1995). Constructing validity: basic issues in objective scale development. Psychological Assessment, 7(3), 309-319.

Costello, A.B., \& Osborne, J. (2005). Best Practices in Exploratory Factor Analysis: Four Recommendations for Getting the Most From Your Analysis. Practical Assessment, Research \& Evaluation. 10, 1-9.

Fintel, D. V. \& Orthofer, A. (2020). Wealth inequality and financial inclusion: Evidence from South African tax and survey records, Economic Modelling, 91, 568-578.

Hinkin, T. R. (1995). A review of scale development practices in the study of organizations. Journal of Management, 21(5), 967-988.

Aduda, J. \& Kalunda, E. (2012). "Financial Inclusion and Financial Sector Stability With Reference To Kenya: A Review of Literature," Journal of Applied Finance \& Banking, SCIENPRESS Ltd, vol. 2(6), 1-8.

Kaiser, H.F. (1974). An Index of Factorial Simplicity. Psychometrika 39, 31-36.

Kapuscinski, A. N., \& Masters, K. S. (2010). The current status of measures of spirituality: a critical review of scale development. Psychology of Religion and Spirituality, 2(4), 191-205.

Morgado, F., Meireles, J., Neves, C., Amaral, A. \& Ferreira, M. (2017). Scale development: Ten main limitations and recommendations to improve future research practices. Psicologia: Reflexão e Crítica. 30(3). 1-20.

Rather, N.A., \& Lone, P.A. (2012). Bottlenecks and problems related to financial inclusion in Madhya Pradesh. Journal of Economics and Sustainable Development, 3(9), 21-24.

Sarma, M. and Pais, J. (2011). Financial Inclusion and Development. Journal of International Development, 23, 613625.

Straub, D., Boudreau, M.C. \& Geffen, D. (2004). Validation guidelines for IS positivist research. Communications of the Association for Information Systems, 13, 380-427.

Basu, P., \& Srivastava, P. (2005). Scaling-Up Microfinance for India's Rural Poor. Development Economics. Policy Research Working Paper; No. 3646. World Bank, Washington DC. DOI: 10.1596/1813-9450-3646. Corpus ID 67814533.

Mandell, L. (2008). The Financial Literacy of Young American Adults: Results of the 2008 National Jumpstart Coalition survey of high school seniors and college students. University of Washington and the Aspen Institute. The Jumpstart Coalition for Personal Financial Literacy.

Park, C., \& Mercado, R. V. (2018). Financial Inclusion: New Measurement and Cross-Country Impact Assessment. ADB Economics Working Paper Series 539/2018. South East Asian Central Banks (SEACEN) Research and Training Centre.

Orissa Journal of Commerce, 42(2) (C) 2021 
Serrao, M., Sequeira, A.H. \& Hans, V. (2012). Designing a Methodology to Investigate Accessibility and Impact of Financial Inclusion. SSRN Electronic Journal. 10.2139/ssrn.2025521.

Smith, A. (2002). The Wealth of Nations. Oxford, England: Bibliomania.com Ltd. Retrieved from the Library of Congress, https://lccn.loc.gov/2002564559.

Government of India (2008). Reserve Bank of India (RBI) Document. Financial Inclusion: Report on Currency and Finance. Chapter 7 (Final) pp. 294 - 348.

Hair, J. F., Jr., Black, W. C., Babin, B. J., \& Anderson, R. E. (2009). Multivariate data analysis (7th ed.). Upper Saddle River, NJ: Pearson Prentice Hall.

Klapper, L., Lusardi, A., \& Van Oudheusden, P. (2015). Financial Literacy around the World. Washington DC: Standard \& Poor's Ratings Services Global Financial Literacy Survey.

Kline, R. B. (2005). Principles and practice of structural equation modeling (2nd ed.). Guilford Press.

Kochaar, S. (2009). Speeding Financial Inclusion, Academic foundation New Delhi.

bttps:// mww.nobelprize.org/prizes/peace/2006/yunus/26090-mubammad-yunus-nobel-lecture-2006-2/ (accessed on 22.01.2021)

https:/ / assets.publishing.service.gov.uk/government/ uploads/system/ uploads/attachment_data/file/272216/6706.pdf (accessed on 25.01.2021)

bttps:// mmwn.indiagrowing.com/Tamil_Nadu/Tirunelveli_District. (accessed on 27.11.2020)

bttps://rbidocs.rbi.org.in/rdocs/content/pdfs/NSFIREPORT100119.pdf. (accessed on 21.11.2020) 